\title{
Evaluation of some nutritional biomarkers of the inmates in grand-bassam prison (Côte d'ivoire)
}

\begin{abstract}
In Côte d'Ivoire, malnutrition is a public health problem, especially for vulnerable populations, particularly the prison population. This study, which aims at assessing the nutritional status of the prisoners in Grand-Bassam (Côte d'Ivoire) using nutritional biomarkers, included 64 inmates against 56 controls. They were aged between 18 and 40 years old. Results showed that the prisoners of Grand-Bassam presented $45.31 \%$ of chronic undernutrition and $20.31 \%$ of acute malnutrition against respectively $5.36 \%$ and $7.15 \%$ among the controls. They were at high risk of infections, inflammation (PINI $>1$ ) and morbidity $(\mathrm{GNRI}<100)$ related to malnutrition. This malnutrition was correlated with an activation of the immune system translated by an increase in white blood cells, especially neutrophils. The prison population of Grand-Bassam requires better care to ensure their well-being.
\end{abstract}

Keywords: nutritional status, biomarkers, prison population, Grand Bassam
Volume 8 Issue 5 - 2018

\section{Rosine A KOUAME, Frédéric K N'DIA, Mathieu N BLEYERE, Jean-Baptiste N OUSSOU, Paul A YAPO}

Laboratory of Physiology, Pharmacology and Pharmacopoeia, Nangui Abrogoua University, Côte d'Ivoire

Correspondence: Bleyere N Mathieu, Laboratory of Physiology, Pharmacology and Pharmacopoeia, Nangui Abrogoua University, 02 BP 80 I Abidjan 02, Côte d'Ivoire, Tel +22545439944, Email chridandre@gmail.com

Received: August 07, 2018 | Published: September 05, 2018

\section{Introduction}

Malnutrition is a public health problem with two billion people suffering from micronutrient deficiency. ${ }^{1}$ In addition, about 925million people are chronically undernourished with very high prevalence in Africa. ${ }^{2}$ For instance, $25.84 \%$ of sub-Sahara african were undernourished. ${ }^{2}$ This undernutrition increases morbidity, aggravates the vital prognosis of healthy subjects and remains the first cause of acquired immunodeficiency in the world. ${ }^{3,4}$ Its evaluation is therefore an important tool for public health and an indicator of a better standard of living. ${ }^{5}$ In Côte d'Ivoire, works on nutritional status have generally focused on the anthropometric parameters of children. ${ }^{6}$ Previous work carried out in the prison population of Grand-Bassam on nutritional status based on anthropometric parameters revealed $14.06 \%$ of undernutrition. ${ }^{7}$ To our knowledge, no study has been undertaken on the nutritional status of the prison population based on biological parameters. To overcome this lack of data and provide informations on the nutritional status of this fringe of the population, this study aims at assessing the nutritional status of carceral population of Grand-Bassam (Côte d'Ivoire) prison using nutritional biomarkers.

\section{Subject and methods}

\section{Subject}

The study population is made up of 64 inmates out of a total of 120 and 56 non-incarcerated individuals (controls) of both sexes aged between 18 and 40, apparently healthy and having signed an informed consent form. Inmates who had a detention period of at least four months were included in this work. However, recently transfused subjects as well as those with chronic diseases (hypertension, diabetes ...), and abnormal hemoglobin pathologies were not included in the study population.

\section{Methods}

\section{Collection of data}

This investigation is a descriptive cross-sectional study carried out in the prison population of Grand-Bassam over the period from
November 2015 to August 2016. From each of the subjects recruited, a blood sample was taken by venipuncture at the crease of the elbow in the morning on an empty stomach. Some blood samples were collected in dry tubes and after centrifugation in order sera were obtained and used for the assays of the biological nutritional parameters. Other blood samples were collected in the tubes containing anticoagulant (EDTA) and used for the immediate determination of leukocyte parameters correlated to nutritional markers.

Nutritional status was assessed using nutritional proteins (albumin and prealbumin) that were associated with inflammation proteins (C-reactive protein or CRP and orosomucoid) and anthropometric data (height and weight) to determine nutritional indexes. The Prognostic Inflammatory and Nutritional Index (PINI) and the Geriatric Nutritional Risk Index (GNRI) made possible to evaluate the risk of inflammation, infection and the risk of morbidity related to undernutrition, respectively. Formulas below were used. ${ }^{8,9}$

$$
\text { PINI }=\frac{C R P(\mathrm{mg} / L) \times \text { Orosomucoid }(\mathrm{mg} / \mathrm{L})}{\text { Albumin }(\mathrm{g} / \mathrm{L}) \times \text { Prealbumin }(\mathrm{mg} / \mathrm{L})}
$$

GNRI $=1.519 \times$ Albuminemia $(\mathrm{g} / \mathrm{L})+0.417 \times$ (current weight $/$ ideal weight) $\mathrm{x} 100$

The ideal weight used in the GNRI was determined using the formulas below. ${ }^{10}$

$$
\text { Ideal weight }(\text { Men })=\text { Height }-100-[(\text { Height }-150) / 4]
$$

Ideal weight $($ Women $)=$ Height $-100-[($ Height -150$) / 2.5]$

Where the height is expressed in centimeter and the result is given in kilograms.

\section{Determination of biological parameters}

Albumin was determined by colorimetry method, prealbumin by spectrophotometry, CRP by agglutination test and orosomucoid by the indirect immunofluorescence technique (IFI).

\section{Statistical analysis}

The results were expressed as the mean associated with the Standard 
Mean Error (ESM). The mean values were compared by the Student's T-test and the proportions by the ratio comparison test ( $\mathrm{G}$ test or loglikehood ratio test) with the Windows version R.2.0.1 software. ${ }^{11}$ The Pearson correlation test established potential relationships between nutritional markers and leukocyte parameters. The significance level used is $5 \%(\mathrm{p}=0.05)$.

\section{Results}

\section{Assessment of nutritional status from nutritional proteins}

Assessment of nutritional status using albumin: The different prevalence of the nutritional status of the two studied populations (prison population and control population) as a function of albuminemia were evaluated and indicated in Table 1 . A very significant difference $(p<0.0001)$ was recorded between the two populations. The lowest average albuminemia estimated at $35.28 \pm 0.55 \mathrm{~g} / \mathrm{L}$ was recorded in the prison population compared to $44.22 \pm 0.73 \mathrm{~g} / \mathrm{L}$ for the control.The results also reported a high prevalence of overall exogenous undernutrition (albumin $<35 \mathrm{~g} / \mathrm{L}$ and $\mathrm{CRP}<24 \mathrm{mg} / \mathrm{L}$ ) which was $32.81 \%$ in the prison population. This global malnutrition was subdivided into severe undernutrition $(1.56 \%)$, moderate undernutrition $(3.12 \%)$ and light malnutrition $(28.12 \%)$. With the exception of severe undernutrition, all other types of undernutrition recorded in the prison population had significantly higher proportions than those in the control population which had only $5.36 \%$ of light malnutrition and a lack of moderate and severe malnutrition. $12.5 \%$ endogenous undernutrition was recorded in inmates' population. This prevalence is significantly higher compared to controls that have not recorded any endogenous malnutrition cases. A very significant difference $(p=0.001)$ was recorded in normal nutritional status between the two populations. The highest proportion observed among controls was $94.64 \%$ compared to $54.69 \%$ among prisoners.

Table I Assessment of nutritional status using albumin in prison and control populations

\begin{tabular}{lllll}
\hline & Albumin (g/L) & $\begin{array}{l}\text { Prison population } \\
\mathbf{N = 6 4}\end{array}$ & $\begin{array}{l}\text { Control population } \\
\mathbf{N}=\mathbf{5 6}\end{array}$ & $\mathbf{p}$ \\
\cline { 2 - 5 } & Mean & $\begin{array}{l}35.28 \pm 0.55 \\
\%(\mathrm{n})\end{array}$ & $\begin{array}{l}44.22 \pm 0.73 \\
\%(\mathrm{n})\end{array}$ & $<0.000 \mathrm{I}(\mathrm{S})$ \\
& $\begin{array}{l}20-25 \\
(\text { severe malnutrition) }\end{array}$ & $1.56(\mathrm{I})$ & $0(0)$ & $0.14 \mathrm{I}(\mathrm{NS})$ \\
$\mathrm{CRP}<24 \mathrm{mg} / \mathrm{L}$ & $\begin{array}{l}25-30 \\
\text { (moderate malnutrition) }\end{array}$ & $3.12(2)$ & $0(0)$ & $0.037(\mathrm{~S})$ \\
& $\begin{array}{l}30-35 \\
\text { (light malnutrition) }\end{array}$ & $28.13(18)$ & $5.36(3)$ & $3.81 .10^{-05}(\mathrm{~S})$ \\
$\mathrm{CRP}>24 \mathrm{mg} / \mathrm{L}$ & $\begin{array}{l}<35 \\
\text { (endogenous malnutrition) }\end{array}$ & $12.5(8)$ & $0(0)$ & $3.14 .10^{-05}(\mathrm{~S})$ \\
$>35($ normal state) & & $54.69(35)$ & $94.64(53)$ & $0.001(\mathrm{~S})$
\end{tabular}

$\mathrm{N}$, total number of the population; n, number observed for each nutritional status; CRP, C-reactive protein; S, Statistically significant difference for $\mathrm{p}<0.05$; NS, statistically insignificant difference for $\mathrm{p}>0.05$.

Assessment of nutritional status using prealbumin: The prevalence of nutritional status using prealbumin is presented in Table 2. Regarding exogenous malnutrition, the results reported no case of severe undernutrition in both populations. The types of undernutrition detected in the prison population were the moderate one $(1.56 \%)$ and mild form $(9.38 \%)$, the total constituting a total of $10.94 \%$ total exogenous malnutrition within that this. These proportions compared to those of controls, were significantly higher at the level of light malnutrition where a proportion of $1.79 \%$ was recorded in the controls against $9.38 \%$ in the prisoners population. However, there was no significant difference in moderate malnutrition between the two populations. As for endogenous malnutrition, it had a higher proportion in the prison population compared to the control $(9.37 \%$ against $3.57 \%$ ), however without any significant difference. The control population showed a higher proportion of normal nutritional status than controls $(92.86 \%$ versus $79.69 \%)$ with no significant difference.

\section{Assessment of the risk of undernutrition using the nutritional indices}

Assessment of the risk of infection and inflammation related to undernutrition using the Prognostic Inflammatory and Nutritional Index (PINI): The results presented in Figure 1 showed that $48.28 \%$ and $46.15 \%$ of malnutrition were recorded respectively from albumin and prealbuminemia. It indicates a low risk of infection and inflammation related to malnutrition in prisoners. These proportions did not show any significant difference between them. No case of moderate or high risk were recorded using the PINI in this study within the prison population.

Assessment of the morbidity risk of undernutrition using the Geriatric Nutritional Risk Index (GNRI): The GNRI values, presented in Figure 2, showed high proportions of low, moderate and high risk of morbidity related to the state of undernutrition of the prisoners. The highest proportions were found in hypoalbuminemic malnutrition with a significant difference in low risk. The highest proportion of undernourished patients with no morbidity risk estimated at $38.46 \%$ was recorded in prisoners with a pre-bovine blood volume lower than $0.22 \mathrm{~g} / \mathrm{L}$.

Correlation between nutritional parameters and leukocyte parameters: Pearson correlation test results between nutritional biomarkers and immune parameters showed a significant $(p<0.05)$ decrease of albuminemia associated with an increase of the number of white blood cells, particularly neutrophils (Table 3 ). In addition, a decrease in GNRI was also accompanied by an increase in the number of white blood cells and polymorphonuclear neutrophils. Other types of white blood cells (eosinophils, monocytes and lymphocytes) did not show significant correlation ( $\mathrm{p}>0.05$ ) with nutritional parameters. 
Table 2 Assessment of nutritional status using prealbumin in both populations

\begin{tabular}{|c|c|c|c|c|}
\hline & Prealbumin (g/L) & $\begin{array}{l}\text { Prison population } \\
N=64\end{array}$ & $\begin{array}{l}\text { Control population } \\
N=56\end{array}$ & $\mathbf{p}$ \\
\hline & \multirow[t]{2}{*}{ Mean } & $0.32 \pm 0.01$ & $0.31 \pm 0.009$ & \multirow{2}{*}{0.564 (NS) } \\
\hline & & $\%(n)$ & $\%(n)$ & \\
\hline \multirow{3}{*}{ CRP $<6 \mathrm{mg} / \mathrm{L}$} & $\begin{array}{l}<0.14 \\
\text { (severe malnutrition) }\end{array}$ & $0(0)$ & $0(0)$ & I (NS) \\
\hline & $\begin{array}{l}0.14-0.17 \\
\text { (moderate malnutrition) }\end{array}$ & $1.56(1)$ & $1.79(\mathrm{I})$ & 0.904 (NS) \\
\hline & $\begin{array}{l}0.17-0.22 \\
\text { (light malnutrition) }\end{array}$ & $9.38(6)$ & $1.79(\mathrm{I})$ & $0.017(S)$ \\
\hline $\mathrm{CRP}>6 \mathrm{mg} / \mathrm{L}$ & $\begin{array}{l}<0.22 \\
\text { (endogenous malnutrition) }\end{array}$ & $9.37(6)$ & $3.57(2)$ & $0.100(\mathrm{NS})$ \\
\hline \multicolumn{2}{|c|}{$>0.22$ (normal state) } & $79.69(5 \mathrm{I})$ & $92.86(52)$ & 0.315 (NS) \\
\hline
\end{tabular}

$\mathrm{N}$, total number of the population; $n$, number observed for each nutritional status; CRP, C-reactive protein; $\mathrm{S}$, statistically significant difference for $\mathrm{p}<0.05$; NS, statistically insignificant difference for $p>0.05$.

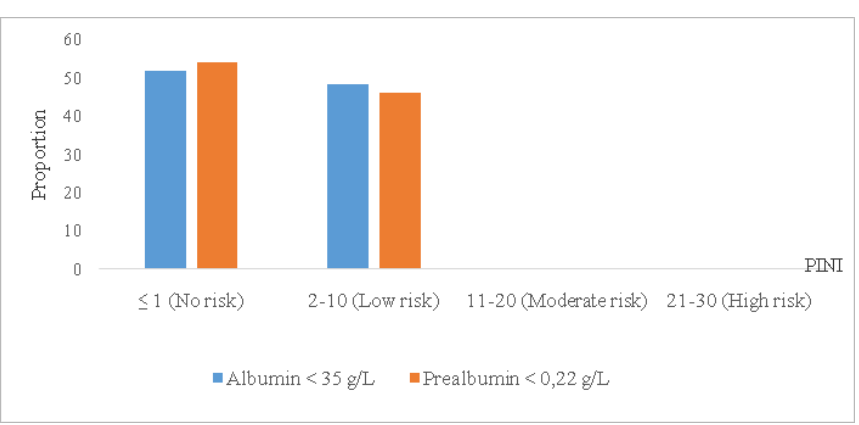

Figure I Proportions of inflammation risk linked to under nutrition of the prison population using the PINI.

PINI, prognostic inflammatory and nutritional index.

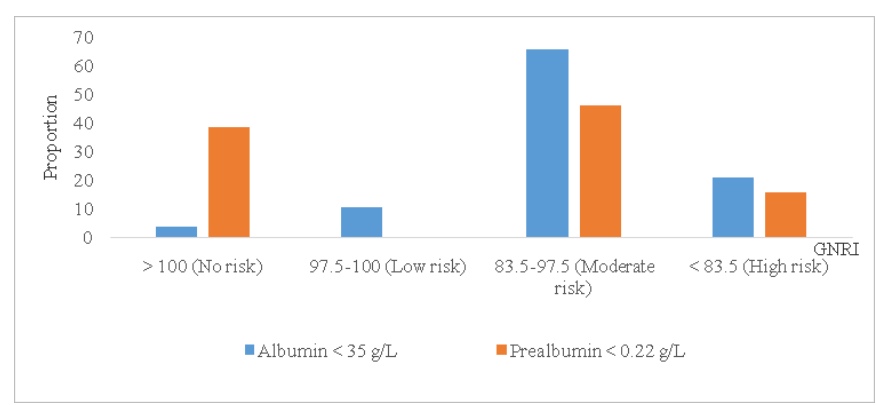

Figure 2 Proportion of morbidity risk related to under nutrition in the prison population from the GNRI.

GNRI, geriatric nutritional risk index; ***, statistically significant difference for $\mathrm{p}<0.000$ I.

\section{Discussion}

The biological evaluation of the nutritional status of the prison population of Grand-Bassam using the albumin concentration made it possible to record a high prevalence of global exogenous undernutrition estimated to $32.81 \%$ against $5.38 \%$ in the controls. From the concentration of prealbumin, global undernutrition was estimated to $10.94 \%$ against $3.56 \%$ in controls. These high prevalences of undernutrition shown by a significant decrease in albumin and prealbumin levels could be explained by a deficiency of dietary amino acid intake. Indeed, in case of exogenous malnutrition due to an insufficient food intake, a lack of amino acids leads to a blockage of the hepatic synthesis of some proteins, depending on the amino acid deficient. Thus, concentration of albumin and prealbumin which are rich in tryptophan are rapidly reduced when this essential amino acid is deficient. ${ }^{12}$ According to these authors, serum albumin and prealbumin concentrations are considered as an indirect reflection of amino acid availability for hepatic protein synthesis. In addition, low concentrations of albumin and prealbumin associated with high levels of CRP resulted in $12.5 \%$ endogenous undernutrition from albumin and $9.37 \%$ from prealbumin within the prison population compared to $0 \%$ and $3.57 \%$ respectively among the controls. This endogenous malnutrition is probably caused by inflammatory diseases. Indeed, according to,$^{13}$ the post-inflammatory variation of these albumin and prealbumin is linked to the transcriptional action of cytokines, especially those of IL-6, IL-1 and TNF $\alpha$, which redirect hepatic synthesis of many proteins promoting those of the inflammation proteins instead of those of nutrition. This leads to a decrease in albumin and prealbumin levels. Thus, the very precarious hygiene and sanitation conditions in the Grand-Bassam prison could justify the inflammatory diseases that cause endogenous malnutrition. ${ }^{14}$

Table 3 Correlation between nutritional parameters and leukocyte parameters in the prison population

\begin{tabular}{lllll}
\hline & Albumin $(\mathbf{g} / \mathbf{L})$ & $\begin{array}{l}\text { Prealbumin } \\
(\mathbf{g} / \mathbf{L})\end{array}$ & PINI & GNRI \\
\hline Leukocytes & $-0.27^{*}$ & - & - & $-0.24^{*}$ \\
Neutrophils & $-0.28 *$ & - & - & $-0.3 I^{*}$ \\
Eosinophils & - & - & - & - \\
Monocytes & - & - & - & - \\
Lymphocytes & - & - & - & -
\end{tabular}

PINI, prognostic inflammatory and nutritional index; GNRI, geriatric nutritional risk index; -, the observed correlation coefficients are not significant $(p>0.05)$ *, significant $\mathrm{p}$ value for $\mathrm{p}<0.05$ 
The difference in prevalence between undernutrition estimated from albumin $(45.31 \%)$ and that estimated from prealbumin (20.31\%), reveals respectively the chronic and acute character of this undernutrition. Prealbumin, because of its short half-life of two days, is the protein marker for biological diagnosis of early undernutrition, while albumin with a half-life of 20 days demonstrates chronic undernutrition. ${ }^{15}$ In sum, $45.31 \%$ of the prisoners of Grand-Bassam would be in a state of chronic malnutrition and $20.31 \%$ in an acute phase which could persist.

The Prognostic Inflammatory and Nutritional Index (PINI) revealed very high risk of infection and inflammation in prisoners with chronic undernutrition (48.28\%) and acute (46.15\%). Undernutrition in this prison could therefore be the source of many infections. Indeed, several studies have shown that undernutrition causes a disruption of the immune system. ${ }^{4,16,17}$ According to these authors, undernutrition causes atrophy of lymphoid tissues that reduce the maturation of lymphocytes. This leads to a decrease in the number and function of circulating leukocytes, thus causing an increase in susceptibility to infections. These immune perturbations could justify the high proportion of risk of infection and inflammation recorded in this mostly malnourished prison population.

As for the Geriatric Nutritional Risk Index (GNRI), it revealed that almost all the undernourished prisoners presented morbidity risks. With these proportions of risk up to the risk of high morbidity, within an apparently healthy prison population, signs of illness could quickly appear. Indeed, undernutrition, the leading cause of acquired immunodeficiency, ${ }^{3}$ would make these undernourished prisoners much more vulnerable. Previously benign underlying diseases would then show signs of worsening and would reveal signs of illness. ${ }^{18,19}$ From the Pearson correlation results obtained, there is a relationship between the nutritional status and the immune system that would be defined as follows: any decrease in the albumin level whether endogenous or exogenous, resulting in undernutrition, would promote infections; hence its correlation with the GNRI which reflects an increased risk of morbidity. These infections stimulate and activate the immune system leading to the proliferation of white blood cells mainly neutrophils which are the first cells mobilized in case of infection. This result is similar to those of $f^{4,5}$ who also described a relationship between nutritional status and the immune system during their respective work.

\section{Conclusion}

The evaluation of the nutritional status of the prison population of Grand-Bassam from biological markers revealed $45.31 \%$ of chronic undernutrition and $20.31 \%$ of acute undernutrition against respectively $5.36 \%$ and $7.15 \%$. in the control. This undernutrition was an association of the exogenous and endogenous type. These high prevalences of undernutrition have exposed prisoners to risks of infection, inflammation and morbidity. Undernutrition in prison was intimately correlated with an activation of the immune system characterized by leukocytosis especially neutrophilia.

\section{Acknowledgments}

We would like to thank the administration of the Grand Bassam civil prison which provided us the necessary staff (nurse, social worker and prison guards) to facilitate the collection of data and also the National Institute of Public Hygiene (INHP) of Port-Bouet
(Ivory Coast) for its contribution in the determination of biological parameters.

\section{Conflict of interests}

Author declares that there is no conflict of interest.

\section{References}

1. WHO. Vitamin and Mineral Nutrition Information System. Genève: WHO; 2009.

2. FAO. L'état de l'insécurité alimentaire dans le monde 2010. Combattre l'insécurité alimentaire lors des crises prolongées. Rome: 2010. p. 63.

3. Lesourd B. Protein undernutrition as the major cause of decreased immune function in the elderly: clinical and functional implications. Nutr Rev. 1995;53(4 Suppl 1): S68-94.

4. Vialettes B. Besoins nutritionnels et apports alimentaires de l'adulte. Evaluation de l'état nutritionnel. Dénutrition. France: Faculté de Médecine de Marseille; 2006. p. 10-16.

5. Nurul H, Ruzita A. Preliminary Survey on nutritional status among University students at Malaysia. Pakistan J Nutr. 2010;9(2):125-127.

6. Kokoré BA, Bleyere MN, Ehile EE. L'anémie nutritionnelle chez les écoliers de trois communes du district d'Abidjan en Côte d'Ivoire. Antropo. 2013;29:49-56.

7. Kouamé AR, N'dia KF, Yapo AP. Assessment of nutritional status and hematologic profile of inmates in grand bassam prison (Ivory coast). World J Pharm Res. 2016;5(8):1546-1555.

8. Ingenbleek Y, Carpentier YA. A prognostic inflammatory and nutritional index scoring critically ill patients. Int J Vitam Nutr Res. 1985;55(1):91101.

9. Bouillanne O, Morineau G, Dupont C, et al. GNRI or Geriatric Nutritional Risk Index: a new index for evaluating at-risk elderly medical patients. Am J Clin Nutr. 2005;82(4):777-783.

10. Lorentz FH. Ein neuer Konstitionsinde. Klin Wschr. 1229;8:348-351.

11. Ihaka R, Gentleman R. A language for data analysis and graphics. $J$ Comput Graph Stat. 1996;5(3):299-314.

12. Coudon C, Giraudet P, Hennache B. Profils protéiques ciblés. Spectra Biologie. 2001;20:19-27.

13. Yeh SS, Schuster MW. Geriatric cachexia: the role of cytokines. Am J Clin Nutr. 1999;70(2):183-197.

14. Sodjinou J, Bitome B, Libam M. Rapport diagnostic des établissements pénitentiaires de Grand-Bassam, d'Abidjan et de Dabou. Côte d'Ivoire: ONG N'GBOADÔ; 2012. p. 22.

15. Férard G, Ingenbleek Y. Place actuelle de la transthyrétine en biologie clinique. Ann Biol Clin. 2003;61:358-362.

16. Chandra RK, Kumari S. Effects of nutrition on the immune system. Nutrition. 1994;10(3):207-210.

17. Amrouche RC. Nutrition et immunité. Institut National de Nutrition, Tunis, Tunisie Journée mondiale de l'immunologie (Tunis, 28/04/2013).

18. Edington J, Boorman J, Durrant ER, et al. Prevalence of malnutrition on admission to four hospitals in England. Clin Nutr. 2000; 19(3):191-195.

19. Schneider SM, Veyres P, Pivot X, et al. Malnutrition is an independent factor associated with nosocomial infections. Br J Nutr. 2004;92(1):105111. 